\title{
Induction of B Cell Responses in the Stomach of Helicobacter pylori-infected Subjects after Oral Cholera Vaccination
}

\author{
Anna Mattsson, ${ }^{*}$ Hans Lönroth, ${ }^{\ddagger}$ Marianne Quiding-Järbrink, ${ }^{\star}$ and Ann-Mari Svennerholm* \\ *Department of Medical Microbiology and Immunology, and ${ }^{\ddagger}$ Department of Surgery, Göteborg University, S-413 46 Göteborg, Sweden
}

\begin{abstract}
We have evaluated the possibility of inducing antibody responses locally in the human stomach as a prerequisite for the development of a vaccine against Helicobacter pylori. Both $H$. pylori-infected and noninfected subjects were immunized with an oral B subunit whole cell (BS-WC) cholera vaccine, and total and vaccine-specific antibody-secreting cells (ASC) were determined by the enzyme-linked immunospot (ELISPOT) technique in cells isolated from the antrum and duodenum, respectively, before and after vaccination. Most of the subjects responded to the vaccination with high frequencies of vaccine-specific ASCs in the duodenum as well as high-serum antibody titers, and no significant differences were seen in the responses between $H$. pyloriinfected and noninfected subjects. When studying the gastric mucosa, on the other hand, there were dramatic differences between the $H$. pylori-infected and the noninfected subjects. Thus, whereas none of the noninfected subjects responded to the immunization in antrum, most of the $H$. pylori-infected subjects had high frequencies of vaccine-specific ASCs in this location after vaccination. Furthermore, the $H$. pylori-infected subjects had strikingly higher (as a mean 80-fold) frequencies of total IgA-secreting cells in antrum than the noninfected subjects, whereas the frequencies of total IgA-secreting cells in the duodenum were comparable between the groups. In conclusion, these results demonstrate the possibility of inducing antibody responses locally in the gastric mucosa of $H$. pylori-infected individuals, a finding with obvious implications for the future development of a therapeutic vaccine against $H$. pylori. (J. Clin. Invest. 1998. 102:51-56.) Key words: antibody secreting cells • ELISPOT • human • antrum • mucosa
\end{abstract}

\section{Introduction}

Infection with Helicobacter pylori has been identified as the main cause of chronic antral gastritis and duodenal ulcer

Part of this work was presented at the 8th International Congress of Mucosal Immunology in San Diego, CA, on 16-20 July 1995.

Address correspondence to Dr. Ann-Mari Svennerholm, Dept. of Medical Microbiology and Immunology, Göteborg University, Guldhedsgatan 10A, S-413 46 Göteborg, Sweden. Phone: 46-31-60-47-24; FAX: 46-31-82-01-60; E-mail: ann-mari.svennerholm@microbio.gu.se

Received for publication 7 March 1997 and accepted in revised form 1 April 1998.

J. Clin. Invest.

(C) The American Society for Clinical Investigation, Inc. 0021-9738/98/07/0051/06 \$2.00

Volume 102, Number 1, July 1998, 51-56

http://www.jci.org
$(\mathrm{DU})^{1}(1,2)$. The bacteria colonize the stomach and metaplastic regions of the duodenum $(3,4)$, and the infection results in strong systemic and usually also mucosal antibody responses (5). In spite of the H. pylori-specific B cell response, the bacteria are not eliminated from the gastric epithelium, and the infection is usually lifelong.

The histologically normal stomach is relatively free of leukocytes (6), whereas $H$. pylori infection leads to a dense infiltration of polymorphonuclear and mononuclear cells (MNCs) and even to formation of lymphoid follicles $(5,7)$. In addition, the frequencies of Ig-containing cells have been found to be substantially increased in the gastric mucosa of patients with active chronic gastritis (8). However, the antigen specificity of these cells has not been determined. According to the concept of a common mucosal immune system, the destination of migrating B cells initially activated in the gut is the intestinal lamina propria and some, but not all, mucosal tissues distant from the initial site of antigen exposure $(9,10)$. Whether the gastric mucosa is a part of this network is not known, and the origin of the infiltrating gastric B cells has not been identified.

In this study we have evaluated the possibility of inducing antibody responses locally in the human stomach as a prerequisite for the development of an $H$. pylori vaccine by means of oral immunization with an inactivated B subunit-whole cell (BS-WC) cholera vaccine $(11,12)$. We now report that oral immunization can elicit specific antibody-secreting cell (ASC) responses in the antral mucosa of $H$. pylori-infected but not of noninfected individuals.

\section{Methods}

Subjects and immunizations. This study was approved by the Ethical Committee at Sahlgrenska University Hospital, Göteborg, Sweden. Eight $H$. pylori-infected (two women and six men, aged 23-38 yr) and seven noninfected (four women and three men, aged 23-50 yr) subjects were recruited under informed consent. H. pylori infection was confirmed by culture of antral biopsies and serology. Two of the H. pylori-infected subjects had DUs, three suffered from non-ulcer dyspepsia, and three had asymptomatic infections. None of the subjects were on any medication at the time of the study. The subjects were immunized twice 2 wk apart with an oral BS-WC cholera vaccine (SBL Vaccine, Stockholm, Sweden), containing $1 \mathrm{mg}$ BS and $10^{11}$ killed vibrios per dose (11). All subjects underwent two complete gastroduodenoscopies; one before administration of the first vaccine dose and the second one $7 \mathrm{~d}$ after the last vaccination. On both occasions, $12-14$ biopsies, $2-3 \mathrm{~mm}$ in diameter ( $\sim 12 \mathrm{mg} /$ biopsy), were collected from the descending part of the duodenum and from the antral mucosa, 3-4 cm proximal to the pyloric sphincter, using a pair of biopsy forceps (FB 24 K; Olympus, Stockholm, Sweden). Antral biopsies were collected from all subjects while duodenal biopsies were

1. Abbreviations used in this paper: ASC, antibody-secreting cell; BS, B subunit; DU, duodenal ulcer; $\mathrm{Hp}-$, noninfected; $\mathrm{Hp}+$, infected with H. pylori; MNC, mononuclear cell; TT, tetanus toxoid; WC, whole cell. 
collected from all of the noninfected subjects and from seven of the eight $H$. pylori-infected subjects. Blood samples were collected at the same time as the biopsies.

In a separate set of experiments four additional $H$. pylori-infected subjects (all men, aged 21-59 yr) were included in the study to evaluate the specificity of the ASCs induced by the vaccination. One of these subjects had DU whereas the other three were asymptomatic.

Isolation of MNCs. MNCs were isolated from the antral and duodenal biopsies as described previously (13). Briefly, the biopsies were cut into small pieces using a scalpel, followed by incubation at $4^{\circ} \mathrm{C}$ for $30 \mathrm{~min}$ in Hank's balanced salt solution (Gibco, Paisley, Scotland) containing $1 \mathrm{mM} \mathrm{CaCl}_{2}, 10 \mathrm{mM}$ dithiothreitol (Sigma Chemical Co., St. Louis, MO), and $0.5 \mathrm{mg} / \mathrm{ml}$ of Bacillus thermoproteolyticus thermolysin (Boehringer Mannheim GmbH, Mannheim, Germany). The remaining tissue fragments were further treated with collagenase/dispase (Boehringer Mannheim), diluted to $1 \mathrm{mg} / \mathrm{ml}$ in Iscove's medium (Biochrom KG, Berlin, Germany) supplemented with $20 \%$ inactivated FCS at $37^{\circ} \mathrm{C}$ for $45 \mathrm{~min}$. Finally, the extracted cells were incubated at $37^{\circ} \mathrm{C}$ for $20 \mathrm{~min}$ in Iscove's medium with 5\% FCS containing $2 \mathrm{mg} / \mathrm{ml}$ of deoxyribonuclease (Sigma Chemical Co.). Isolated cells were washed and resuspended in Iscove's medium supplemented with $5 \%$ FCS and $100 \mu \mathrm{g} / \mathrm{ml}$ gentamicin (Essex Läkemedel AB, Stockholm, Sweden).

Detection of total and specific Ig-secreting cells. The numbers of total $\operatorname{IgA}$ and antigen-specific ASCs (IgA-ASCs to BS, IgA- and IgM-ASCs to WC) in the cell suspensions were determined by the enzyme-linked immunospot (ELISPOT) technique $(14,15)$. In some experiments we also determined the frequencies of ASCs reacting with two control antigens, i.e., the tetanus toxoid (TT) and BSA. To detect BS-specific ASCs, individual wells of nitrocellulose-bottomed 96-well Millititer plates (Millipore Corp., Bedford, MA) were coated with $100 \mu \mathrm{l}$ of $3 \mu \mathrm{M}$ monoganglioside 1 (Sigma) at $4^{\circ} \mathrm{C}$ overnight, washed, and incubated with $2.5 \mu \mathrm{g} / \mathrm{ml}$ of recombinantly produced BS (16) at $37^{\circ} \mathrm{C}$ for $2 \mathrm{~h}$ on the day of analysis. For determination of TT- and BSA-specific ASCs, wells were coated with $20 \mu \mathrm{g} / \mathrm{ml}$ of TT (SBL Vaccine) or $0.5 \%$ BSA (wt/vol) dissolved in PBS and incubated at room temperature overnight. For the detection of ASCs specific for whole bacteria, wells were first treated with $50 \mu \mathrm{l} / \mathrm{well}$ of $10 \mu \mathrm{g} / \mathrm{ml}$ of poly-L-lysine (Sigma Chemical Co.) and incubated at room temperature for $30 \mathrm{~min}$. The wells were then emptied and $50 \mu \mathrm{l}$ of an inacti- vated WC cholera vaccine (preparation S1549; Institut Mérieux, Lyon, France) lacking BS was added to each well at a concentration of $5.5 \times 10^{9}$ bacteria/ml (17). The plates were then centrifuged at 2,000 rpm for $5 \mathrm{~min}$ whereupon $50 \mu \mathrm{l}$ of $0.5 \%$ (wt/vol) glutaraldehyde (Sigma Chemical Co.) in cold PBS was added to the wells and incubated at room temperature for $30 \mathrm{~min}$. After two washes with PBS, the wells were incubated with $200 \mu \mathrm{l}$ of $\mathrm{H}_{2} \mathrm{O}$ containing $1 \% \mathrm{FCS}$ and $0.1 \mathrm{M}$ glycine for $30 \mathrm{~min}$. The plates were finally washed, filled with $1 \%$ FCS in PBS, and frozen at $-30^{\circ} \mathrm{C}$. For the detection of total IgAsecreting cells, wells were coated with $5 \mu \mathrm{g} / \mathrm{ml}$ of affinity-purified goat antibodies to the $\mathrm{F}\left(\mathrm{ab}^{\prime}\right)_{2}$ fragment of human IgG (Jackson ImmunoResearch Laboratories, Inc., West Grove, PA) in PBS. After washing and blocking of the plates with 5\% FCS in Iscove's medium, cells were added to the wells in quadruplicates in concentrations ranging from $10^{2}$ (total IgA) to $4 \times 10^{4}$ (antigen-specific) MNCs/well. Cells were incubated in the plates at $37^{\circ} \mathrm{C}$ overnight in air with $7.5 \%$ $\mathrm{CO}_{2}$, and after thorough washes horseradish peroxidase-conjugated antibodies to human IgA or IgM (Southern Biotechnology Associates, Birmingham, AL) were added and plates incubated at room temperature for $3 \mathrm{~h}$. Wells were then washed and plates were developed with $100 \mu \mathrm{l} /$ well of chromogen substrate containing $0.3 \mathrm{mg} / \mathrm{ml}$ of 3-amino-9-ethylcarbazole (Sigma Chemical Co.) and $0.015 \%$ (vol/ vol) $\mathrm{H}_{2} \mathrm{O}_{2}$. Spots were enumerated under low magnification $(\times 40)$ and the frequency of ASCs was calculated from four wells and adjusted to spot-forming cells per $10^{5} \mathrm{MNCs}$ (for total IgA-secreting cells) or per $10^{4}$ total IgA-secreting cells (for antigen-specific ASCs). A more than twofold increase in frequency of vaccine-specific ASCs after vaccination was considered to be significant.

Detection of vaccine-specific antibodies in serum. Serum samples were analyzed for antitoxin and antibacterial titers by a monoganglioside 1-ELISA and a vibriocidal assay, respectively, as previously described $(18,19)$. Serial dilutions of pre- and postvaccination specimens were tested in duplicates and greater than or equal to twofold titer raises were considered significant (12). For control purposes we also analyzed the serum samples for $H$. pylori-specific antibodies according to the protocol of Hamlet et al. (20).

Statistical analyses. Differences in distribution of total $\operatorname{IgA}$ secreting cells as well as differences in serum and mucosal antibody responses to the vaccine between the two study groups were evaluated by the Mann-Whitney hypothesis test.

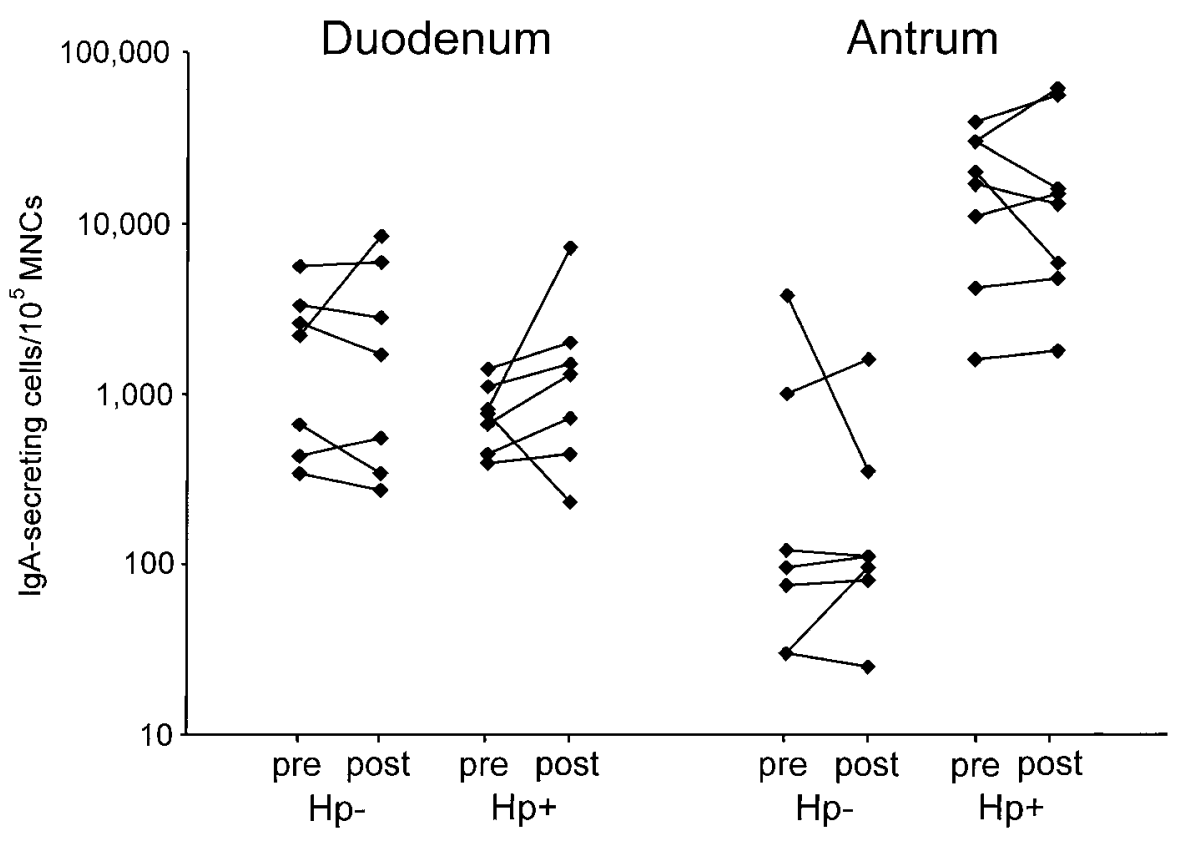

Figure 1. Frequencies of total IgA-secreting cells in duodenal and antral biopsies from $H$. pylori-infected $(\mathrm{Hp}+)$ and noninfected $(\mathrm{Hp}-)$ subjects before and after vaccination. Points represent the mean of each subject's pre- and postimmunization values and are expressed as numbers of IgAsecreting cells per $10^{5}$ MNCs. 


\section{Results}

Total IgA-producing cells. MNCs were extracted from duodenal and antral biopsies by enzymatic dispersion and the frequencies of total IgA producing cells were determined by the ELISPOT technique. A pool of 12 duodenal biopsies from noninfected subjects yielded a mean of $11 \times 10^{5}$ viable MNCs (range 7-16 $\times 10^{5}$ ), and corresponding biopsies from infected subjects $13 \times 10^{5} \mathrm{MNCs}$ (range 9-20 $\times 10^{5}$ ). The extraction of similar numbers of antral biopsies resulted in $3 \times 10^{5}$ MNCs (range $1.5-4.3 \times 10^{5}$ ) from the noninfected subjects and in $7.3 \times 10^{5} \mathrm{MNCs}\left(\right.$ range $3.5-17 \times 10^{5}$ ) from the $H$. pyloriinfected subjects. The frequencies of total IgA-secreting cells in the duodenum were approximately the same in the two study groups (Fig. 1). However, the $H$. pylori-infected subjects had $\sim 80$ times higher frequencies of total IgA-secreting cells than the noninfected subjects in the antrum $(P<0.001) ; \sim 10 \%$ of the MNCs isolated in antrum of the infected subjects were found to secrete $\operatorname{IgA}$. Indeed, most of the H. pylori-infected subjects had higher frequencies of IgA-secreting cells in the gastric mucosa than in the duodenum. In most cases, the frequencies of total IgA-secreting cells in antrum and duodenum did not change appreciably during the 3-wk study period. However, in one of the noninfected subjects a 10-fold decrease in the frequency of total $\operatorname{IgA}$-secreting cells was seen in antrum and in one of the $H$. pylori-infected subjects a 9-fold increase in the frequency of total $\operatorname{IgA}$-secreting cells was found in duodenum 1 wk after completed vaccination (Fig. 1).

Vaccine-induced ASCs in duodenal biopsies. The isolated MNCs were also assayed for the presence of vaccine-specific ASCs. In about half of the subjects BS-specific ASCs were seen in duodenum before immunization (30-850 ASCs $/ 10^{4}$ total IgA-ASCs), while no such ASCs were detected in the remaining subjects. Most of the subjects, i.e., 11 out of 14 , responded to the vaccine with substantially increased frequencies of BS-specific ASCs producing IgA in duodenum (Fig. 2).
Almost all the subjects had anti-WC reactive ASCs (20-940 ASCs $/ 10^{4}$ total IgA-ASCs) before vaccination. Nevertheless, a majority of the subjects, i.e., 9 out of 14 , responded with increased numbers of IgA- and IgM-ASCs (data not shown for IgM) specific for whole vibrios in duodenum (Fig. 2). The frequencies of WC-specific IgM-ASCs were very similar to those of the IgA-ASCs and all of the subjects that responded with IgA-ASCs also responded with IgM-ASCs. All but one of the subjects that responded to the WC also responded to the BS, even though the anti-BS response generally was more pronounced than the response to the WC component. No significant differences were found in the ability to respond to the BS or the WC component in the duodenum between $H$. pyloriinfected and noninfected subjects.

Vaccine-induced ASCs in antral biopsies. MNCs extracted from antral biopsies were also assayed for vaccine-reactive ASCs. No vaccine-specific ASCs were seen in antral biopsies from the noninfected subjects before vaccination and the peroral cholera vaccine did not induce any ASC responses either to the $\mathrm{BS}$ or the WC component in the antral mucosa of these subjects (Fig. 3). In contrast, BS- and WC-reactive ASCs were found in a majority of the $H$. pylori-infected subjects before immunization (Fig. 3). Two oral doses of cholera vaccine induced substantially increased BS-specific ASC responses in five of the eight $H$. pylori-infected subjects. The highest responses were seen in the two DU patients. Five of the $H$. pylori-infected subjects also responded to the vaccine with increased frequencies of WC-specific ASCs.

Specificity of the vaccine-induced ASCs. To determine if the vaccine-induced ASCs that reacted with BS and WC actually were the result of a specific immune response, MNCs from four additional subjects were analyzed for reactivity not only with the vaccine antigens, i.e., BS and $\mathrm{WC}$, but also with two unrelated antigens, i.e., TT and BSA. All of these subjects responded to the vaccination with increased frequencies of ASCs reacting with the BS in the duodenum (Table I). Fur-

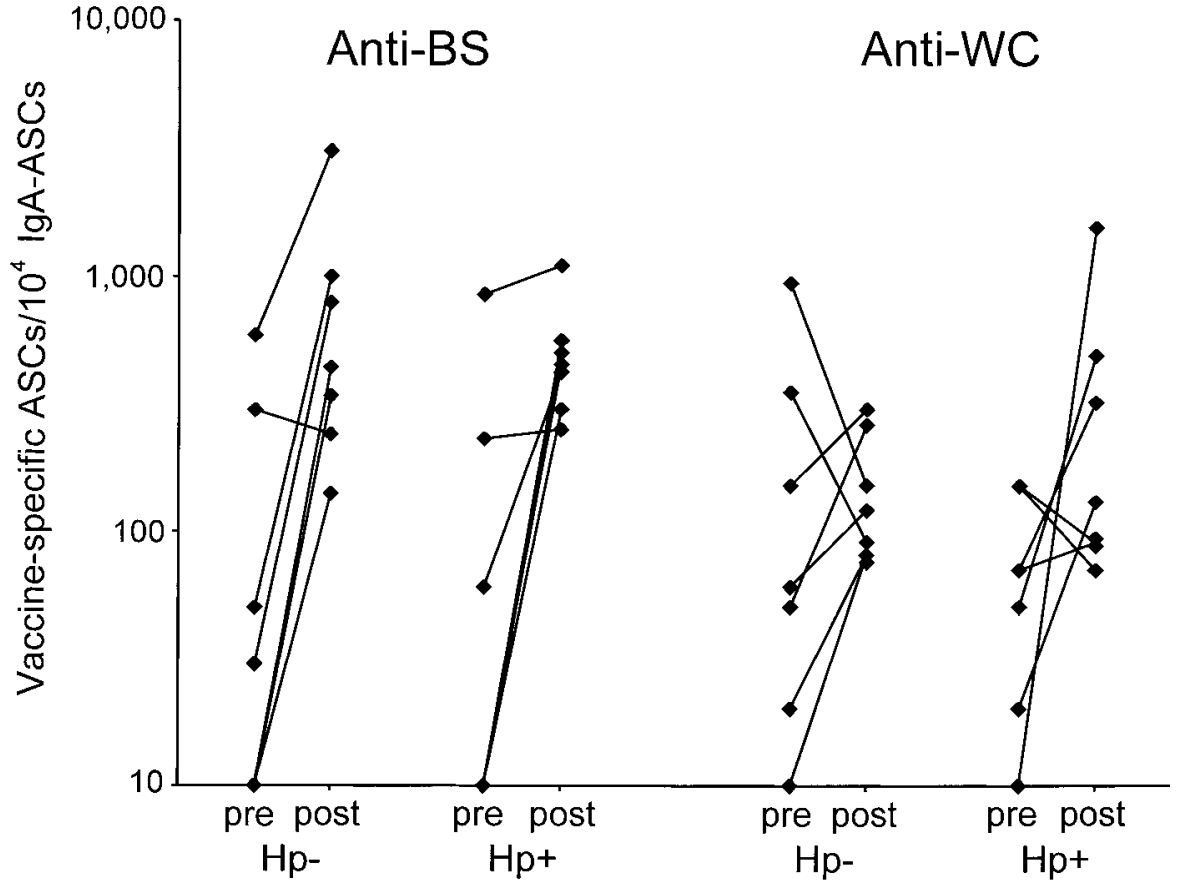

Figure 2. Frequencies of ASCs specific for the cholera BS and the WC component in duodenum before and after immunization. H. pylori-infected $(\mathrm{Hp}+)$ and noninfected $(\mathrm{Hp}-)$ subjects were vaccinated with an oral BS-WC cholera vaccine and biopsies were collected before and $7 \mathrm{~d}$ after vaccination. MNCs were isolated from the biopsies and assayed for frequencies of vaccinespecific IgA-secreting cells. Data are expressed as numbers of vaccine-specific ASCs per $10^{4}$ total IgA-secreting cells. 


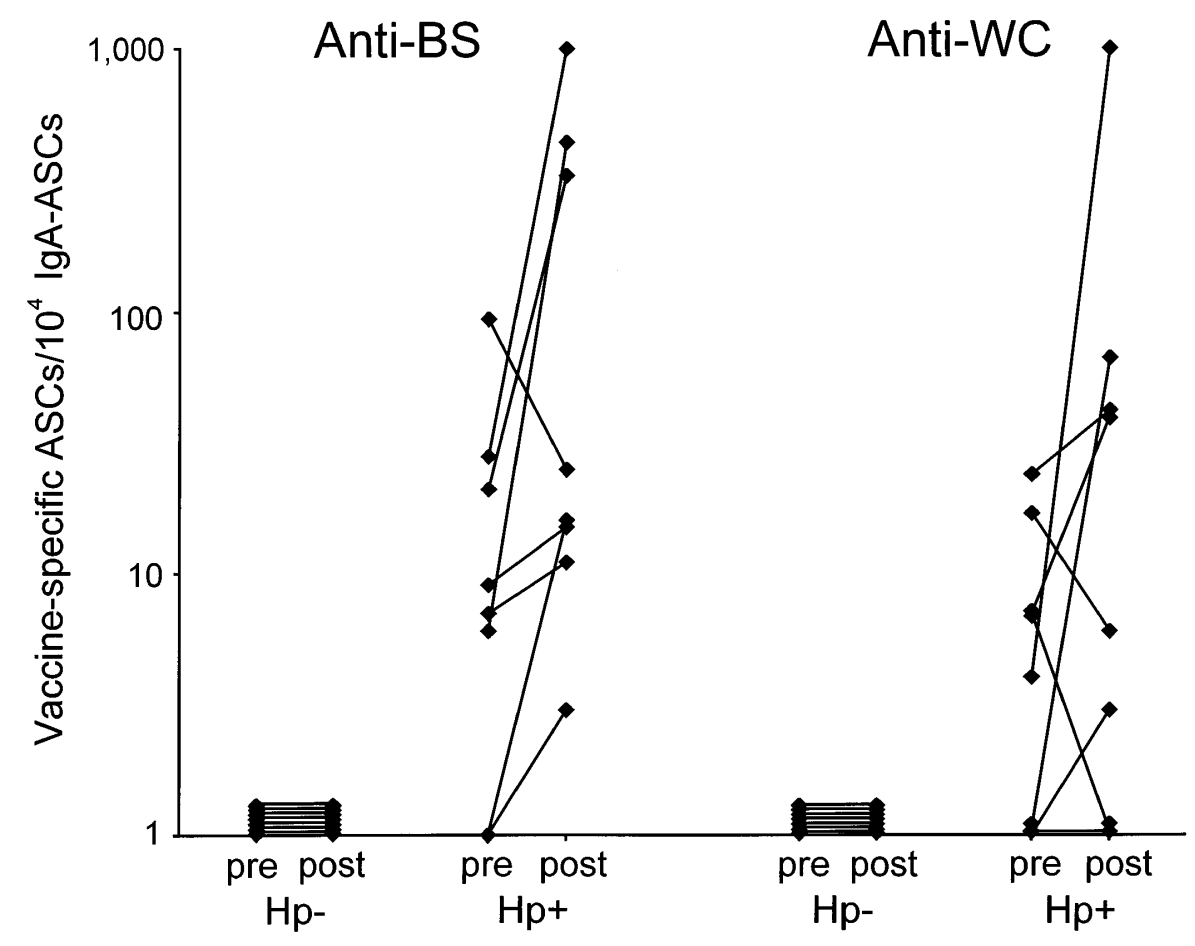

Figure 3. Frequencies of ASCs specific for the cholera BS and the WC component in antrum before and after immunization. H. pylori-infected $(\mathrm{Hp}+)$ and noninfected $(\mathrm{Hp}-)$ subjects were vaccinated with an oral BS-WC cholera vaccine and biopsies were collected before and $7 \mathrm{~d}$ after vaccination. MNCs were isolated from the biopsies and assayed for frequencies of vaccinespecific IgA-secreting cells. Data are expressed as numbers of vaccine-specific ASCs per $10^{4}$ total IgA-secreting cells. thermore, one of the subjects also responded with an increased frequency of duodenal ASCs reacting with the WC component. When studying antibody responses against the control antigens we found that none of the subjects responded to the immunization with increased frequencies of BSA-reactive ASCs. However, TT-reactive ASCs were seen in two of the subjects after vaccination. In the antrum, one of the subjects responded with a higher frequency of BS-reactive ASCs after vaccination and another one with an increased frequency of WC-reactive ASCs. As in the duodenum, none of the subjects responded to the immunization with ASCs reacting with the control antigen BSA while the subject who responded with BS-reactive ASCs also had TT-reactive ASCs after immunization (Table I). Even though the frequencies of antigen-specific ASCs were increased by the vaccination, the number of total IgA-secreting cells $/ 10^{5} \mathrm{MNCs}$ did not vary significantly between biopsies collected before and after immunization.

Table I. Fold Increase in Frequencies of ASCs Reacting with Vaccine Antigens (BS and WC) and Unrelated Antigens (TT and BSA) after Vaccination with an Oral BS-WC Cholera Vaccine

\begin{tabular}{|c|c|c|c|c|c|c|c|c|}
\hline \multirow[b]{3}{*}{ Subject No. } & \multicolumn{4}{|c|}{ Duodenum } & \multicolumn{4}{|c|}{ Antrum } \\
\hline & \multicolumn{2}{|c|}{$\begin{array}{l}\text { Vaccine } \\
\text { antigens }\end{array}$} & \multicolumn{2}{|c|}{$\begin{array}{l}\text { Control } \\
\text { antigens }\end{array}$} & \multicolumn{2}{|c|}{$\begin{array}{l}\text { Vaccine } \\
\text { antigens }\end{array}$} & \multicolumn{2}{|c|}{$\begin{array}{r}\text { Control } \\
\text { antigens }\end{array}$} \\
\hline & BS & WC & TT & BSA & BS & WC & $\mathrm{TT}$ & BSA \\
\hline 1 & 47.0 & $\leq 1$ & $\leq 1$ & $\leq 1$ & $\leq 1$ & $\leq 1$ & $\leq 1$ & $\leq 1$ \\
\hline 2 & 21.0 & 38.0 & 13.0 & $\leq 1$ & $\leq 1$ & $\leq 1$ & $\leq 1$ & $\leq 1$ \\
\hline 3 & 4.8 & $\leq 1$ & $\leq 1$ & $\leq 1$ & 2.2 & $\leq 1$ & 2.1 & $\leq 1$ \\
\hline 4 & 5.8 & $\leq 1$ & 3.2 & $\leq 1$ & $\leq 1$ & 3.2 & $\leq 1$ & $\leq 1$ \\
\hline
\end{tabular}

Antibody responses in serum. The antitoxic and antibacterial antibody responses in serum from the vaccinees were also analyzed. All but 2 of the 15 subjects responded to the vaccination with significantly increased levels of antibodies against the BS component in serum. However, both of the subjects who did not respond with antitoxic serum antibodies responded with increased frequencies of BS-specific ASCs in the duodenum. Eight of the subjects also responded with increased vibriocidal titers and five other subjects had high vibriocidal titers $(>80)$ before immunization. Vaccination of individuals with high pretiters has been shown previously to result in much lower frequencies of responders than vaccination of individuals with low pretiters (21). However, there was no significant difference in antibody responses in serum between infected and noninfected subjects (Table II). Only one of the five subjects with high vibriocidal titers in serum before vaccination also had high frequencies of vaccine-specific ASCs before immunization.

As a control, the serum samples were also analyzed for $H$. pylori-specific antibodies before and after vaccination. However, the antibody titers against $H$. pylori in serum did not change in any of the subjects during the study period.

\section{Discussion}

The finding that a microorganism, i.e., H. pylori, is the major cause of chronic gastritis and DUs has resulted in a vast interest in developing a vaccine against the bacterium. Since $H$. $p y$ lori is noninvasive, such a vaccine should preferentially induce a strong mucosal immune response locally in the stomach where the bacteria are located. In agreement with this notion, animal studies have demonstrated a correlation between local production of secretory IgA and protection against $H$. felis infection after oral immunization (22). However, to date no study has evaluated the possibility of inducing immune re- 
Table II. Antibody Titers in Serum against the WC Component and the BS in $\mathrm{H}$. pylori-infected $(\mathrm{Hp}+)$ and Noninfected $(\mathrm{Hp}-)$ Subjects before and after Immunization with an Oral $B S$-WC Cholera Vaccine

\begin{tabular}{lccccc}
\hline & \multicolumn{2}{c}{ Vibriocidal titer } & & \multicolumn{2}{c}{ Anti-BS IgA titer } \\
\cline { 2 - 3 } \cline { 5 - 6 } Study group & pre & post & & pre & post \\
\hline $\mathrm{Hp}-$ & $45^{*}$ & 120 & & 6.9 & 55 \\
& $(5.4-370)$ & $(12-1100)$ & & $(5.2-9.2)$ & $(13-230)$ \\
$\mathrm{Hp}+$ & 120 & 580 & & 8.7 & 190 \\
& $(5.7-2600)$ & $(61-5500)$ & & $(4.9-16)$ & $(110-320)$ \\
& & & & & \\
\hline
\end{tabular}

*Data are expressed as geometric means $( \pm 1 \mathrm{SD})$.

sponses locally in the human stomach against deliberately delivered antigens. To allow such an evaluation we have used an oral cholera vaccine as a model vaccine, since this vaccine has been shown previously to induce strong immune responses locally in the human intestine (23-25).

To investigate whether the inflammation that is present in the antrum in the majority of $H$. pylori-infected individuals may affect the possibility of inducing gastric antibody responses, the cholera vaccine was administered to both $H$. $p y$ lori-infected and noninfected subjects. The $H$. pylori-infected subjects in this study had different manifestations of their infection and even though we did not determine the degree of antral inflammation in these subjects we have, in a parallel study, not been able to detect any difference in the degree of antral inflammation between asymptomatic $H$. pylori carriers and patients with DU (26).

The oral cholera vaccine has been shown previously to induce substantial numbers of BS-specific ASCs in the duodenum of healthy volunteers (23). In accordance, a majority of the subjects in the present study also responded with BS-specific ASCs in the duodenum after two oral immunizations and no differences were seen between the infected and the noninfected subjects. In addition, we also recorded significant ASC responses against the WC component in most of the immunized subjects, i.e., in $H$. pylori-infected as well as noninfected subjects. Although the BS-WC cholera vaccine and the WC component alone have been shown to induce highly significant protection against cholera (27), intestinal ASC responses against the bacterial component of the vaccine have not been documented earlier. In sharp contrast to the duodenal responses, BS-specific ASC responses in antrum could only be seen in the $H$. pylori-infected vaccinees, whereas the healthy noninfected subjects did not develop a detectable BS-specific ASC response in the antrum after vaccination. Similarly, only the $H$. pylori-infected, but not the noninfected subjects, developed detectable ASC responses against the WC component in antrum, suggesting that only individuals with an inflamed gastric mucosa can develop significant immune responses against orally administered antigens. However, it is possible that the noninfected subjects may have responded against the vaccine in the stomach although at such a low level that it could not be detected by our method.

The vaccine-specific mucosal response in this study was not merely the result of an unspecific activation, since the frequencies of ASCs reacting with the unrelated protein BSA did not change. To our surprise, some of the subjects had increased frequencies of ASCs reacting with another unrelated antigen, TT, after immunization. However, it seems unlikely that the increase in TT- or vaccine-specific ASCs is the result of polyclonal activation, since the frequencies of total $\operatorname{IgA}$-secreting cells did not change significantly after vaccination. One explanation for the increase in TT-reactive ASCs might be that there actually are cross-reactive epitopes in BS and TT or that the immunization induced polyreactive antibodies in some volunteers.

In the noninfected stomach, there are few lymphoid cells, whereas $H$. pylori infection leads to infiltration of granulocytes as well as B and T cells (1). Indeed, we could document as much as 80 -fold higher frequencies of $\operatorname{IgA}$-secreting cells in the antrum of the $H$. pylori-infected than in the noninfected subjects. In fact, most $H$. pylori-infected individuals had higher frequencies of IgA-secreting cells in the antrum than in duodenum. Inflammation of the gastric mucosa also results in increased expression of secretory component, the transporter of polymeric Ig over the epithelium (28), and formation of lymphoid follicles $(5,7)$. Subsequent studies have shown that, in contrast to total IgA-ASCs, the frequencies of total IgGsecreting cells remain virtually unchanged in $H$. pylori-induced gastritis (28a), suggesting that $H$. pylori infection primarily promotes IgA responses.

Despite the dense infiltration of ASCs into the gastric mucosa in $H$. pylori infection, the physiological relevance of the antibodies produced has been questioned due to high concentrations of gastric acid and proteolytic enzymes in the human stomach. However, the gastric mucus layer contains a $\mathrm{pH}$ gradient ranging from an acidic $\mathrm{pH}$ in the lumen to a near-neutral $\mathrm{pH}$ on the surface of the epithelial cells (29) where the $H$. pylori bacteria are located and the antibodies are needed. In addition, we have shown recently that a large proportion of the IgA found in gastric juice is SIgA which is comparatively resistant to proteolytic degradation (30).

It seems reasonable that the $H$. pylori-associated gastritis facilitates the induction of $\mathrm{B}$ cell responses. However, at this stage we can only speculate about the mechanisms behind this observation. Although minute amounts of intact proteins can be transported through the normal gastric epithelium $(31,32)$, a common result of gastrointestinal inflammation is decreased mucosal integrity, which in turn may facilitate uptake of antigens via the gastric epithelium in the $H$. pylori-infected stomach. Hypothetically, antigen presentation and lymphocyte differentiation could then take place in the local lymphoid follicles. Furthermore, recent hypotheses predict that it is more likely for antigens presented in the setting of an inflammation to be regarded as foreign and to elicit immune responses (33). Alternatively, the cytokines produced during the inflammatory response to $H$. pylori, which have been shown to upregulate the expression of endothelial adhesion molecules $(34,35)$, might lead to an increased infiltration of leukocytes. Thus, after oral immunization, the activation of B cells and differentiation into ASCs might be initiated in the inductive sites of the small intestine, and then the upregulated expression of endothelial adhesion molecules in the $H$. pylori-infected stomach might result in an increased migration of plasma cell precursors into the gastric mucosa.

Several animal studies have demonstrated that protective immunity against $H$. pylori $(36)$ and $H$. felis infection $(37,38)$ can be achieved by oral immunization with whole $H$. pylori bacteria or purified antigens given together with appropriate 
adjuvants. These studies have suggested the possibility of inducing protective immune responses against $H$. pylori in noninfected animals as well as the possibility of eliminating an already established infection. However, in this study we were only able to induce gastric ASC responses in subjects that were infected with $H$. pylori and not in noninfected subjects. This difference between human and animal studies could be due to different possibilities of inducing gastric immune responses between species or to reflux of antibodies produced in the duodenum that may be effective in protection against Helicobacter infection.

In conclusion, our study demonstrates that it is possible to induce specific mucosal B cell responses against deliberately administered antigens locally in the antrum, at least in $H$. $p y$ lori-infected individuals with inflamed gastric mucosa, thereby supporting the possibility of developing an effective oral, therapeutic vaccine against $H$. pylori. Our results suggest that the local $H$. pylori-induced inflammation is a prerequisite for induction of antibody responses in the stomach, as suggested by the dense infiltration of IgA-secreting cells only in $\mathrm{H}$. pyloriinfected individuals.

\section{Acknowledgments}

We thank all the subjects who participated in the study and the staff at the Department of Gastroenterology, Sahlgrenska Hospital, for their invaluable help. The skillful assistance of Ingela Ahlstedt and Camilla Johansson is gratefully acknowledged.

This work was supported by grants from the Bank of Sweden Tercentenary Foundation and the Swedish Medical Research Council.

\section{References}

1. Blaser, M.J. 1992. Hypotheses on the pathogenesis and natural history of Helicobacter pylori-induced inflammation. Gastroenterology. 102:720-727.

2. Marshall, B.J., and J.R. Warren. 1984. Unidentified curved bacilli in the stomach of patients with gastritis and peptic ulceration. Lancet. 1:1311-1315.

3. Steer, H.W. 1984. Surface morphology of the gastroduodenal mucosa in duodenal ulceration. Gut. 25:1203-1210.

4. Wyatt, J.I., B.J. Rathbone, M.F. Dixon, and R.V. Heatley. 1987. Campylobacter pyloridis and acid induced gastric metaplasia in the pathogenesis of duodenitis. J. Clin. Pathol. 40:841-848.

5. Wyatt, J.I., and B.J. Rathbone. 1988. Immune response of the gastric mucosa to Campylobacter pylori. Scand. J. Gastroenterol. Suppl. 142:44-49.

6. Owen, D.A. 1986. Normal histology of the stomach. Am. J. Surg. Pathol. 10:48-61.

7. Stolte, M., and S. Eidt. 1989. Lymphoid follicles in antral mucosa: immune response to Campylobacter pylori? J. Clin. Pathol. 42:1269-1271.

8. Valnes, K., P. Brandtzaeg, K. Elgjo, and R. Stave. 1986. Quantitative distribution of immunoglobulin-producing cells in gastric mucosa: relation to chronic gastritis and glandular atrophy. Gut. 27:505-514.

9. Czerkinsky, C., and J. Holmgren. 1994. Exploration of mucosal immunity in humans: relevance to vaccine development. Cell. Mol. Biol. 40(Suppl. 1):37-44.

10. McGhee, J.R., J. Mestecky, M.T. Dertzbaugh, J.H. Eldridge, M. Hirasawa, and H. Kiyono. 1992. The mucosal immune system: from fundamental concepts to vaccine development. Vaccine. 10:75-88.

11. Holmgren, J., A.-M. Svennerholm, M. Jertborn, J. Clemens, D.A. Sack, R. Salenstedt, and H. Wigzell. 1992. An oral B subunit: whole cell vaccine against cholera. Vaccine. 10:911-914.

12. Jertborn, M., A.-M. Svennerholm, and J. Holmgren. 1992. Safety and immunogenicity of an oral recombinant cholera B subunit-whole cell vaccine in Swedish volunteers. Vaccine. 10:130-132.

13. Nordström, I., M. Quiding, B. Kjellsson, A. Kilander, E. Ahlfors, J. Holmgren, and C. Czerkinsky. 1990. Thermolysin treatment; an improved dispersion technique for isolating functional lymphoid cells from human intestinal tissues. In Advances in Mucosal Immunology. T.T. McDonald, S.J. Challacombe, P.W. Bland, C.R. Strokes, R.V. Heatley, and A. Mowat, editors. Kluwer Academic Publishers, Dordrecht. 103-104.

14. Czerkinsky, C.C., L.A. Nilsson, H. Nygren, O. Ouchterlony, and A. Tarkowski. 1983. A solid-phase enzyme-linked immunospot (ELISPOT) assay for enumeration of specific antibody-secreting cells. J. Immunol. Methods. 65:
109-121.

15. Sedgwick, J.D., and P.G. Holt. 1983. A solid-phase immunoenzymatic technique for the enumeration of specific antibody-secreting cells. J. Immunol. Methods. 57:301-309.

16. Sanchez, J., and J. Holmgren. 1989. Recombinant system for overexpression of cholera toxin B subunit in Vibrio cholerae as a basis for vaccine development. Proc. Natl. Acad. Sci. USA. 86:481-485.

17. Jertborn, M., A.-M. Svennerholm, and J. Holmgren. 1996. Intestinal and systemic immune responses in humans after oral immunization with a bivalent B subunit-O1/O139 whole cell cholera vaccine. Vaccine. 14:1459-1465.

18. Svennerholm, A.-M., J. Holmgren, R. Black, M. Levine, and M. Merson. 1983. Serologic differentiation between antitoxin responses to infection with Vibrio cholerae and enterotoxin-producing Escherichia coli. J. Infect. Dis. 147:514-522.

19. McIntyre, O.R., and J.C. Feely. 1964. Passive serum protection of the infant rabbit against experimental cholera. J. Infect. Dis. 114:468-475.

20. Hamlet, A.K., K.I.M. Erlandsson, L. Olbe, A.-M. Svennerholm, V.E.M. Backman, and A.B. Pettersson. 1995. A simple, rapid and highly reliable capsule-based ${ }^{14} \mathrm{C}$ urea breath test for diagnosis of Helicobacter pylori infection. Scand. J. Gastroenterol. 30:1058-1063.

21. Sanchez, J.L., A.F. Trofa, D.N. Taylor, R.A. Kuschener, R.F. DeFraites, S.C. Craig, M.R. Rao, J.D. Clemens, A.-M. Svennerholm, J.C. Sadoff, and J. Holmgren. 1993. Safety and immunogenicity of the oral, whole cell/recombinant B subunit cholera vaccine in North American volunteers. J. Infect. Dis. 167:1446-1449.

22. Lee, C.K., R. Weltzin, W.D. Thomas, Jr., H. Kleanthous, T.H. Ermak, G. Soman, and J.E. Hill. 1995. Oral immunization with recombinant Helicobacter pylori urease induces secretory $\operatorname{IgA}$ antibodies and protects mice from challenge with Helicobacter felis. J. Infect. Dis. 172:161-172.

23. Quiding, M., I. Nordström, A. Kilander, G. Andersson, L.A. Hanson, and J. Holmgren. 1991. Intestinal immune responses in humans. Oral cholera vaccination induces strong intestinal antibody responses and interferon-gamma production and evokes local immunological memory. J. Clin. Invest. 88:143-148.

24. Svennerholm, A.-M., M. Jertborn, L. Gothefors, A.M. Karim, D.A. Sack, and J. Holmgren. 1984. Mucosal antitoxic and antibacterial immunity after cholera disease and after immunization with a combined B subunit-whole cell vaccine. J. Infect. Dis. 149:884-893.

25. Svennerholm, A.-M., D.A. Sack, J. Holmgren, and P.K. Bardhan. 1982. Intestinal antibody responses after immunization with cholera B subunit. Lancet. 1:305-308

26. Hamlet, A., A.-C.E. Thoreson, A.-M. Svennerholm, and L. Olbe. 1996. Gastric metaplasia and duodenal H. pylori infection in asymptomatic carriers and duodenal ulcer patients. Gut. 39:A57. (Abstr.)

27. Clemens, J.D., D.A. Sack, J.R. Harris, J. Chakraborty, M.R. Khan, B.F. Stanton, M. Ali, F. Ahmed, M. Yunus, and B.A. Kay. 1988. Impact of B subunit killed whole-cell-only oral vaccines against cholera upon treated diarrhoeal illness and mortality in an area endemic for cholera. Lancet. 1:1375-1379.

28. Valnes, K., P. Brandtzaeg, K. Elgjo, and R. Stave. 1984. Specific and nonspecific humoral defense factors in the epithelium of normal and inflamed gastric mucosa. Gastroenterology. 86:402-412.

28a. Mattsson, A., M. Quiding-Järbrink, H. Lönroth, and A.-M. Svennerholm. 1998. Antibody-secreting cells in the stomachs of symptomatic and asymptomatic Helicobacter pylori-infected subjects. Infect. Immun. 66:2705-2712.

29. Quigley, E.M., and L.A. Turnberg. 1987. pH of the microclimate lining human gastric and duodenal mucosa in vivo. Studies in control subjects and in duodenal ulcer patients. Gastroenterology. 92:1876-1884.

30. Mattsson, A., A. Tinnert, A. Hamlet, H. Lönroth, I. Bölin, and A.-M. Svennerholm. 1998. Specific antibodies in sera and gastric aspirates of symptomatic and asymptomatic Helicobacter pylori infected subjects. Clin. Diagn. Lab. Immunol. 5:288-293.

31. Curtis, G.H., and D.G. Gall. 1992. Macromolecular transport by rat gastric mucosa. Am. J. Physiol. 262:G1033-G1040.

32. Hatz, R.A., K.J. Bloch, P.R. Harmatz, P.A. Gonnella, P.D. Ariniello, and W.A. Walker. 1990. Divalent hapten-induced intestinal anaphylaxis in the mouse enhances macromolecular uptake from the stomach. Gastroenterology. 98:894-900.

33. Matzinger, P. 1994. Tolerance, danger, and the extended family. Annu. Rev. Immunol. 12:991-1045.

34. Kelly, C.P. 1993. Leukocyte adhesion in gastrointestinal inflammation. Curr. Opin. Gastroenterol. 9:962-970.

35. Springer, T.A. 1994. Traffic signals for lymphocyte recirculation and leukocyte emigration: the multistep paradigm. Cell. 76:301-314.

36. Marchetti, M., B. Arico, D. Burroni, N. Figura, R. Rappuoli, and P. Ghiara. 1995. Development of a mouse model of Helicobacter pylori infection that mimics human disease. Science. 267:1655-1658.

37. Ferrero, R.L., J.-M. Thiberge, M. Huerre, and A. Labigne. 1994. Recombinant antigens prepared from the urease subunits of Helicobacter spp.: evidence of protection in a mouse model of gastric infection. Infect. Immun. 62: 4981-4989.

38. Michetti, P., I. Corthesy-Theulaz, C. Davin, R. Haas, A.C. Vaney, and M. Heitz. 1994. Immunization of BALB/c mice against Helicobacter felis infection with Helicobacter pylori urease. Gastroenterology. 107:1002-1011. 